\title{
Bilişsel Davranış̧ı Terapi Yaklaşımının Film Analizi Yöntemiyle İncelenmesi
}

\section{Using Film Analysis Method for an Examination to Cognitive Behavior Therapy Approach}

\author{
Mehmet BOYACI*, Tahsin ILLHAN**
}

\begin{abstract}
Öz: Bilişsel Davranışçı Terapi (BDT) dünya genelinde olduğu gibi Türkiye'de de yaygın bir biçimde uygulanan ve hakkında araştırmalar yapılan bir terapi yaklaşımıdır. BDT depresyonun tedavisiyle başlayan ve günümüzde uyku bozukluğundan, saldırganlığa kadar birçok psikolojik sorunun tedavisinde uygulanan bir yaklaşımdır. Bu çalışmanın temel amacı; Aaron Temkin Beck tarafından geliştirilen BDT yaklaşımının temel felsefesini incelemek ve film analizi yardımıyla kuramın temel kavramlarına ve uygulamasına örneklendirme oluşturmaktır. Bu çalışmada nitel araştırma yöntemlerinden doküman incelemesi kullanılmıştır. Araştırmada 1997 yapımı en iyi senaryo ödülü dâhil olmak üzere iki dalda Oscar ödülünü kazanmış Can Dostum/Good Will Hunting filmi BDT yaklaşımı açısından incelenmiştir. Filmde saldırgan davranış problemi olan üstün yetenekli ancak okulu bırakmış bir genç olan Will ve terapisti Sean arasındaki ilişki anlatılmaktadır. Filmdeki olaylar ve diyaloglar üzerinden BDT'nin temel kavramları somut bir biçimde örneklendirilmeye çalışılmıştır. Ayrıca filmdeki roller üzerinden terapist danışan ilişkisi de ele alınmıştır. Sonuç bölümünde yapılan bütün analizler alanyazın doğrultusunda tartışılmıştır.
\end{abstract}

Anahtar Kelimeler: Bilişsel Davranışçı Terapi, film analizi, psikolojik yardım arama, saldırganlık, doküman analizi.

\begin{abstract}
The Cognitive Behavioral Therapy (CBT), on which many research studies have been carried out, is a widespread method in Turkey as well, as it is around the world. The CBT is an approach used for many psychological disorders from insomnia to aggression besides treatment of depression. The main aim of this study is to examine the philosophical core of the CBT approach developed by Aaron Temkin Beck and form an exemplification for the application and basic concepts of the theory through the film analysis. In the study one of the qualitative research methods document analysis were used. In this research, the movie of "Good Will Hunting" released in 1997 which has won two Oscars including the best screenplay, has been analyzed in terms of the CBT approach. The movie is about the relation between Will who is a highly gifted young but having dropped out of school beside having an aggressive behavioral problem and his therapist Sean. The basic concepts of the CBT have been tried to exemplified corporally through the facts and dialogues in the movie. Furthermore, the therapist -client relation has been examined as well through the roles in the movie. All analyses in the final part have been discussed in line with the literature.
\end{abstract}

Keywords: Cognitive Behavior Therapy, film analysis, psychological help seek, aggressiveness, document analysis.

\section{Giriş}

Birey toplum içersinde diğer insanlarla işletişim kurarak yaşamını sürdürmekte ve ihtiyaçlarını karşılamaktadır. Bireylerin birbirleriyle kurmuş oldukları bu iletişim sürecinde kimi zaman anlaşmazlıklar da yaşanabilmektedir (Hunt ve Colander, 2015). İnsanlar karşılaştıkları bu anlaşmazlıkların üstesinden gelebilmek için profesyonel bir yardıma ihtiyaç duyabilirler. İnsanların sorunlarının çözümünde onlara yardımcı olmak amacıyla yaygın olarak kullanılan terapi yaklaşımlarından birisi de Bilişsel Davranışçı Terapi (BDT) yaklaşımıdır (Blom ve diğ.,

* Dr., Gazi Üniversitesi, Gazi Eğitim Fakültesi, Ankara-Türkiye, e-posta: mehmetboyaci1984@ gmail.com

** Doç. Dr., Gaziosmanpaşa Üniversitesi, Eğitim Fakültesi, Tokat-Türkiye, e-posta: tahsinilhan73@gmail.com 
2015; Corey, 2015; El-Alaoui ve diğ., 2015; Murdock, 2012). BDT’ye göre bireyin yaşadığ duygusal ve davranışsal problemler bireyin düşünce yapısından kaynaklanmaktadır. Dolayısıyla bireyin sorunlu olan bu düşünce yapısı değiştirilince duygusal ve davranışsal sorunlar da ortadan kalmaktadır (Beck, 2006). Bu sebeple BDT'de terapist bireyin uyumunu bozan davranışına neden olduğu düşünülen sorunlu düşünce yapılarıyla çalışılmaktadır (Murdock, 2012; Sharf, 2012).

$\mathrm{Bu}$ çalışmada BDT'nin temel kavramlarına ve uygulamalarına bir örneklendirme oluşturması açısından iki dalda Oscar ödülü kazanmış "Can Dostum/Good Will Hunting” isimli film analiz edilmiştir. Günümüzde filmlerden eğitim, psikoloji ve psikolojik danışma gibi insanı ve toplumu yakından ilgilendiren farklı alanlarda yararlanılmaktadır (Berk, 2009; Horzum, 2011; Koch ve Dollarhide, 2000; Morsünbül, 2015; Sharp, Smith ve Cole, 2002). Filmler insan yaşamını bir yönüyle resmetmekte kimi zaman da gerçek bir hayat hikâyesinden yola çıkarak filmler oluşturulmaktadır. Filmler psikoloji alanında (Aka ve Gençöz, 2010; Şenol-Durak ve Fışıloğlu, 2007; Smithikrai, 2016) ve psikolojik danışman eğitiminde de (Kağnıcı, 2015; Koch ve Dollarhide, 2000) kullanılmaktadır. Filmler hem sinema terapi hem de terapi sürecine yardımcı bir araç olarak alanyazında son yıllarda giderek artan bir biçimde kullanılmaktadır (Berk, 2009; Hankir, Holloway, Agius ve Zaman, 2015; Horzum, 2011; Tümlü ve Voltan-Acar, 2014). Koch ve Dollardhide (2000) filmlerin insan yaşamını yansıtması açısından insanları anlamak adına iyi bir örnek oluşturduklarını ifade etmektedir. Filmler yardımıyla birey yaşadığı olaylara farklı açılardan bakabilmekte, farklı çözüm yollarını ve bu çözüm yollarının olası sonuçlarını somut bir biçimde gözlemleyebilmektedir (Aka ve Gençöz, 2010). Bu açıdan bakıldığında yapılan çalışmanın psikolojik danışman eğitimine ve psikoloji alanına katkı sağlayacağı düşünülmektedir.

Bu çalışmada Matematik alanında üstün yetenekleri bulunan, ancak saldırgan davranış problemleri nedeniyle eğitimine devam edemeyen, üniversite de temizlik görevlisi olarak çalışan Will Hunting/Matt Damon ve terapisti Sean Maguire/Robin Williams arasındaki ilişki BDT yaklaşımına göre incelenmiştir. Filmin başrol oyuncusu Will Hunting özellikle Matematik alanında üstün yetenekleri olmasına rağmen saldırgan davranış problemleri yüzünden birçok kez 1slah evine gönderilmiş ve okulu bırakmıştır. Bu araştırmada hem toplumda oldukça yaygın olarak görülen saldırganlık ve zorbalık (De Rubeis ve Granic, 2012; Feindler ve Engels, 2011; Olweus, 2013) gibi davranış problemlerine örnek oluşturması hem de psikolojik danışman ile danışan arasındaki ilişkiyi ele alması açısından Can Dostum filmi seçilmiştir. Saldırgan davranış sorunu olan danışanlarla çalışırken hem bireysel hem de grupla psikolojik danışma uygulamalarında BDT yaygın olarak kullanılmaktadır (Feindler ve Engel, 2011; Redondo, Martinez-Catena ve Andres-Pueyo, 2012; Tekinsav-Sütçü, Aydın ve Sorias, 2010). Araştırmada öncelikli olarak BDT'nin temel kavramları açılanmış ve filmdeki bazı sahnelerin analizi yoluyla film BDT'ye göre değerlendirilmiştir.

\section{Aaron Temkin Beck ve Bilişsel Davranış̧ı Terapi Yaklaşımı}

Bilişsel Davranışçı Terapi'nin temelleri 1950'li yıllarda Amerikalı Psikiyatri Profesörü Aaron Temkin Beck tarafından atılmıştır (Sharf, 2012). Depresyonun tedavisiyle başlayan Bilişsel Davranış̧̧ı Terapi (BDT) günümüzde uyku problemlerinden, sosyal fobiye kadar neredeyse bütün psikolojik sorunların tedavisinde yaygın olarak kullanılmaktadır (Blom ve diğ., 2015; Dinç, 2012; El Alaoui ve diğ., 2015; O’Donohue ve Fisher, 2009). Beck depresif bireylerle çalışırken, depresif bireylerin yaşam olaylarına karşı olumsuz bir yanlılık içerisinde olduklarını gözlemlemiştir. Beck bu çalışmalarının neticesinde; depresyonun nedenini Bilişsel Üçlü terimiyle formüle etmiştir. Bilişsel Üçlü en basit anlatımıyla bireyin, kendisini, dünyayı ve geleceği olumsuz bir biçimde değerlendirmesi olarak tanımlanabilir (Murdock, 2012; Sharf, 2012) . Özetlemek gerekirse BDT'ye göre; depresyonun ya da başka bozuklukların nedeni duygusal ya da fizyolojik değildir, problemlerin asıl nedeni bireyin olumsuz düşünceleridir.

BDT, düşünce sistemlerinin bireylerin duygularını ve davranışlarını belirlediğine inan bir terapi yaklaşımıdır (Corey, 2015; Murdock, 2012; O'Donohue ve Fisher, 2009). Beck'e (2006) göre bireyin yaşanan bir olaya vermiş olduğu duygusal tepkiler, o olaya yüklenen anlama 
bağlı olarak değişmektedir. Başka bir anlatımla aynı olay farklı bireyler tarafından farklı biçimde algılanıp farklı bir tepkiyle karşılanabilmektedir. BDT tüm davranışların ve daha özel olarak uyumsuz davranış ve ruhsal bozuklukların oluşmasında, çevresel uyaranların etkisini göz ardı etmemekle birlikte, çevresel uyaranların nasıl algılandığının, yani bilişsel süreçlerin önemini vurgulamaktadır. Bilişsel yaklaşımda kişiliğin de bilişsel yapı ve şemalar tarafından biçimlendirildiği vurgulanmaktadır (Gökçakan ve Gökçakan, 2005). Başka bir ifadeyle, BDT de duygu ve davranışların ortaya çıkmasında bilişsel yapıların önemli olduğu vurgulanmaktadır. Birey olayı bilişsel süreçlerinde nasıl değerlendiriyorsa duyuşsal ve davranışsal tepkisini de ona göre vermektedir. Bilişsel süreçlerin nasıl işlediğine ilişkin açıklamalar ilerleyen bölümlerde örnekleriyle detaylı bir biçimde sunulmuştur.

BDT'de terapist ile danışan arasındaki ilişkinin tedavi sürecinin başarıya ulaşmasında önemli olduğu vurgulanmaktadır (Corey, 2015). Beck (2006) BDT'yi terapist ve danışanın problemi bir takım olarak birlikte çalışarak tanımladıkları ve çözdükleri bir psikoterapi yaklaşımı olarak tanımlamaktadır. Birey Merkezli yaklaşımla benzer bir biçimde BDT'de de terapi sürecinin başarılı olabilmesi için terapist ve danışan arasındaki ilişki; içtenlik, empati, koşulsuz kabul ve karşılıklı güvene dayalı olmalıdır (Beck, 2006, Corey, 2015). Danışma sürecinde danışanın topluma uyumunu bozan bilişsel çarpıtmaların ortaya çıkarılmasında ve değiştirilmesinde terapist ile danışan işbirliği içersinde çalışmaktadırlar. Beck bu durumu Birlikte Deneme olarak açıklamaktadır (Beck, 2006). Ayrıca BDT'de terapist, danışanların inanç ve tutumlarının onların duygulanım ve davranış şekillerini nasıl etkilediğini anlamalarına yardımcı olan bir rehber ve katalizör görevi görmektedir (Sharf, 2012). Başka bir ifadeyle BDT'de terapinin amaçlarına ulaşabilmesi için terapötik işbirliği önkoşuldur, yani terapinin amacına ulaşması için ilk önce güvene dayalı sağlam bir terapötik ilişki oluşturulmalıdır. Ayrıca danışanların danışma sürecinde aktif rol oynamaları teşvik edilir.

Beck’e (2006) göre Bilişsel Yapı üç bölümden oluşmaktadır. Bu üç bölüm; görünen kısımda olan Otomatik Düşünceler, temelde daha derinde olan Temel Inançlar ve otomatik düşüncelerle temel inançların ortasında yer alan Ara Inançlardan oluşmaktadır. BDT'de terapi sürecinde; danışanlara kendi düşünce yapısını, özellikle de olumsuz otomatik düşüncelerini tanımlamaları, gözlemlemeleri ve takip etmeleri öğretilir. Bilişsel davranışçı yaklaşıma göre; olumsuz düşünceler ortadan kaldırıldığında ya da değiştirildiğinde, duygusal ve davranışsal sorunlar da otomatik olarak ortadan kaybolacaktır (O'Donohue ve Fisher, 2009). Terapi sürecinde danışan; aktif sokratik diyalogda bulunma, ödev yapma, varsayımlar ile ilgili veri toplama, bu verilerin kaydını tutma, alternatif yorumlar getirme tekniklerini kullanarak otomatik düşüncelerin kendi lehinde ve aleyhinde olan kanıtlarını incelemek üzere eğitilirler (Corey, 2015; Gökçakan ve Gökçakan, 2005; Sharf; 2012). BDT hakkında yapılan bu kısa açıklamadan sonra bu araştırmada film analizinden yararlanılarak BDT'nin temel kavramları açıklanmaya ve somutlaştırılmaya çalışılmıştır.

\section{Yöntem}

Bu çalışma yönetmenliği Gus Van Sant tarafından yapılan iki Oscar ödüllü, orijinal adı "Good Will Hunting" olan "Can Dostum" filminin BDT yaklaşımına dayanarak analiz edildiği betimsel bir çalışmadır. Çalışmada nitel araştırma yöntemlerinden biri olan doküman incelemesi kullanılmıştır. Doküman incelemesinde, araştırılması amaçlanan olgular hakkında bilgi veren yazılı ve görsel materyallerin analizini içermektedir. Doküman incelemesinde yalnızca yazılı materyal değil film, video ve fotoğraf gibi görsel materyaller de kullanılmaktadır (Goodson ve Walker, 1988; Yıldırım ve Şimşek, 2013). Nitel araştırmalarda kullanılan video ya da film analizi gibi yöntemler araştırılan konuya ilişkin daha detaylı veri toplanmasına yardımcı olmaktadır (Goodson ve Walker, 1988).

\section{İşlem}

$\mathrm{Bu}$ çalışmada BDT'nin temel kavramlarını ve uygulamasını film analizi yöntemi ile örneklendirmek amaçlanmıştır. Alanyazında var olan bilgi birikimine katkıda bulunmak ve bu alanda çalışan araştırmacılara farklı bir bakış açısı sunmak maksadıyla, BDT'nin kavramları 
Can Dostum isimli filmin analizi yardımıyla somutlaştırılmaya çalışılmıştır. Analiz sürecinde filmde BDT'nin temel kavramlarına örnek oluşturabilecek bölümler ve diyaloglar araştırmacılar tarafından incelenmiş ve BDT'nin temel kavramlarına göre değerlendirilmiştir. $\mathrm{Bu}$ amaç doğrultusunda, filmde yer alan çeşitli sahneler ve diyaloglar BDT'nin kavramları ile ilişkili olmasına göre gruplandırılmış ve analiz edilmiştir. Filmde bazı sahnelerin değerlendirilmesi yoluyla; bilişsel yapı, bilişsel çarpıtmalar, terapötik ilişki, bilişsel şemalar, temel inançlar, otomatik düşünceler gibi BDT'nin bazı temel kavramları ve terapi süreci açılanmıştır. Filmde BDT'nin bu kavramlarına ilişkin daha belirgin sahneler olduğu için bu kavramlar üzerinden terapi süreci açıklanmıştır.

\section{Bulgular}

Orijinal adı "Good Will Hunting" olan ve Türkçeye "Can Dostum" olarak çevrilen film Amerikan yapımıdır. Film gösterime girdiği 1997 senesinde çok sevilmiş ve en iyi senaryo ödülü dâhil iki dalda Oscar ödülü kazanmıştır. Filmin başkahramanlarından Will Hunting (Matt Damon) üniversitede temizlik görevlisi olarak çalışmaktadır. Will çok zekidir ve araştırma yapmayı çok sevmektedir. Will'in saldırgan davranış problemleri bulunmaktadır arkadaşlarıyla birlikte mahalledeki farklı gruplarla kavgaya etmektedirler. Bu sebeple Will kanunla sürekli problem yaşamaktadır ve karışmış olduğu bir kavga sonucunda cezaevine gönderilmiştir. Will'in matematik kabiliyetini fark etmiş olan üniversitedeki bir profesör bir şartla Will'in terapi alması karşıllı̆ında ona kefil olur ve cezaevinden çıkarılmasını sağlar. Will anlaşmayı istemeyerek de olsa kabul etmek durumda kalır. Filmde Will diğer başrol oyuncusu olan terapisti Sean Maguire (Robin Williams) ile birlikte yaşamına yeniden yön vermeye başlayacaktır. Bu süreçte yeni tanıştığı kız arkadaşı Skylar(Minnie Driver) da ona destek olmaya çalışacaktır. Filmin demografik bilgileri ve konusuna ilişkin bilgiler Tablo 1'de sunulmuştur. Tablo 1'deki bilgiler filmin kapağından alınmıştır.

Tablo 1. Filmle İlgili Demografik Bilgiler

\begin{tabular}{ll}
\hline Yönetmen & Gus Van Sant \\
Yapımcı & Lawrence Bender \\
Senaristler & Matt Damon ve Ben Affleck \\
Oyuncular & Matt Damon, Robin Williams, Minnie Driver, Ben Affleck, Stellan Skasgard. \\
Orijinal Dil & İngilizce \\
Süre & 126 Dk. \\
Ülke & Amerika Birleşik Devletleri \\
\hline
\end{tabular}

Filmin başkahramanı Will'in okulda ve başarısız olmasına yol açan ve sürekli sorunlar yaşamasına neden olan saldırgan davranış problemi bulunmaktadır. Yapılan araştırmalarda toplumda şiddet, saldırganlık ve zorbalık gibi davranış problemlerine sıklıkla rastlandığını göstermektedir (Stefanakou, Tsiantis ve Tsiantis, 2014; Olweus, 2013). Filmde terapisti rolündeki Sean, Will'in saldırgan davranışlarından kurtulması ve hayatını kontrol edebilmesi için çalışmaktadır. Will çok çabuk sinirlenebilmekte ve kavga etmekten çekinmemektedir. Bu sebeple poliste kabarık bir suç kaydı bulunmaktadır. Öfkenin ve saldırgan davranışın çevredekilere zararı olduğu kadar, öfkeli kişilerin kendilerine de zararı bulunmaktadır. Alanyazında öfkeli ve saldırgan olmanın kişiye verdiği zararları bildiren pek çok çalışma bulunmaktadır (De Rubeis ve Granic, 2012; Feindler ve Engel, 2011; Redondo ve diğ., 2012 Tekinsav-Sütçü ve diğ., 2010). Filmde de Will bu saldırgan davranışları yüzünden birçok kez ceza almış ve eğitimini yarıda bırakmak zorunda kalmıştır.

Zorbalık ve şiddet gibi saldırganca davranışlar yaralanma, akademik başarısızlık ve okul terki gibi bireyin yaşamını doğrudan etkileyen farklı zorluklara yol açabilmekte ve bu tip davranışların nasıl önlenebileceği araştırılmaktadır (Boyacı, 2016; De Rubeis ve Granic, 2012; Redondo ve diğ., 2012). Bireyin yaşamını bu denli olumsuz biçimde etkileyen saldırgan 
davranışlara ise öfke duygusunun neden olduğu bilinmektedir. BDT'ye göre yaşanan olayla hissedilen öfke duygusu arasında doğrudan bir ilişki bulunmamaktadır. Öfke duygusunun ortaya çıkmasına aslında bilişsel süreçler neden olmaktadır (Tekinsav-Sütçü ve diğ., 2010). Filmin başkahramanı Will Hunting çocukluk yıllarında alkol sorunu olan üvey babasının şiddetine maruz kalmıştır. Aile içinde veya okul ortamında şiddete tanıklık eden veya maruz kalan ve şiddeti normal bir davranış kalıbı olarak kabul eden bireyler öfke yaşadıklarında şiddete başvurabilmektedirler (Tekinsav-Sütçü ve diğ., 2010). BDT açısından film genel olarak değerlendirildiğinde; Will'in erken çocukluk yaşantıları onun davranışlarını belirlemede önem taşımaktadır, çünkü bu dönemde geçirilen yaşantılar sonucunda bireyin hayata ilişkin temel inançları ve bilişsel şemaları oluşmaktadır (Beck, 2006; Murdock, 2012). Filmde Analiz edilen sahnelere ilişkin liste Tablo 2'de sunulmuştur.

Tablo 2. Filmde Analiz Edilen Sahnelerin Tümüne İlişkin Liste

\begin{tabular}{l|l|l}
\hline Sahneler & Filmdeki Gösterim Zamanı & Sahne İçeriği \\
\hline 1 & 84. Dk. & Bilişsel Yap1 \\
2 & 87. Dk. & Felaketleştirme \\
3 & 85. Dk. & Falcılık \\
4 & 57. Dk. & Hep ya da Hiç Biçiminde Düşünme \\
5 & 30. Dk. ve 41. Dk. & Saldırgan Davraş \\
6 & 87. Dk. & Etiketleme \\
7 & 50. Dk. & Aşırı Genelleme \\
8 & 33. Dk. ve 111.Dk. & Terapötik İlişki \\
\hline
\end{tabular}

\section{Bilişsel Yapt}

BDT'nin önemli kavramlarının başında bilişsel yapı gelmektedir. Bireyin bilişsel yapısı çocukluktan itibaren gelişmektedir. Ayrıca bilişsel yapı bireyin içinde yaşadığı aile ortamını ve çevresini yansıtmaktadır (O'Donohue ve Fisher, 2009). BDT'ye göre bilişsel yapı üç bölümden oluşmaktadır; temel inançlar, ara inançlar ve otomatik düşünceler (Murdock, 2012). Temel inançlar koşulsuz, katı ve değişime dirençli olmaları sebebiyle de yaşamın ilerleyen dönemlerinde bireyin topluma uyumunu bozucu bir hale gelebilmektedir. Ayrica bazı temel inançlar çeşitli yaşam olayları sonucunda harekete geçip farklı olumsuz duygulara ve psikolojik sorunlara neden olabilmektedirler (Sharf, 2012). Temel inançların daha iyi anlaşılması ve somutlaştırılması için filmin başkahramanı olan Will'in Bilişsel Yapısı örneklerle açıklanmıştır. Filmin başkahramanı olan Will çocukluğunda üvey babası tarafindan sistemli olarak şiddete maruz kalmıştır. Beck (2006) olumsuz temel inançları iki kategoride değerlendirmektedir; çaresizlik ve sevilmeme inançlarıdır. Will çocukluğunda şiddet gördüğü ve yetiştirme yurtlarında büyüdüğü için sevilmeme temel inançlarından "Değersizim" inancını taşımaktadır.

Filmin 84. dakikasında Will'in değersizlik temel inancı kendini göstermektedir. Will'in kız arkadaşı Skylar California'da tıp eğitimi alacağını ve Will'in de onunla California'ya gelmesini ister. Will kız arkadaşının teklifini kız arkadaşını çok sevmesine ve onunla California'ya gitmek istemesine rağmen reddeder. Skylar nedenini sorduğunda Will şöyle cevap verir: "Gelecek hafta California'ya gittiğimizde hakkımda beğenmediğin bir şey bulabilirsin. Bunu teklif etmemiş olmayı dileyebilirsin, ama çok ciddi bir şey olduğundan geri alamazsın. Ben de California'da aslında beni istemeyen biriyle kalırım”. Bilişsel davranışçı yaklaşıma göre bireyin olaylara verdiği tepkileri bilişsel yapıları belirlemektedir. Bilişsel yapıyı oluşturan temel inançlar değişime dirençli oldukları için kimi zaman uyum bozucu bir biçimde çalışabilmektedirler (Beck, 2006). Will'in değersiz olduğuna ilişkin temel inancıda onun hayatına ilişkin bazı kararları almasını engellemektedir. Will'in sevme-sevilme konusundaki bilişsel yapısı daha iyi anlaşılması için BDT’ye göre değerlendirilmiş ve Şekil 1'de sunulmuştur. 
Şekil 1. Will Hunting'in Bilişsel Yapısı

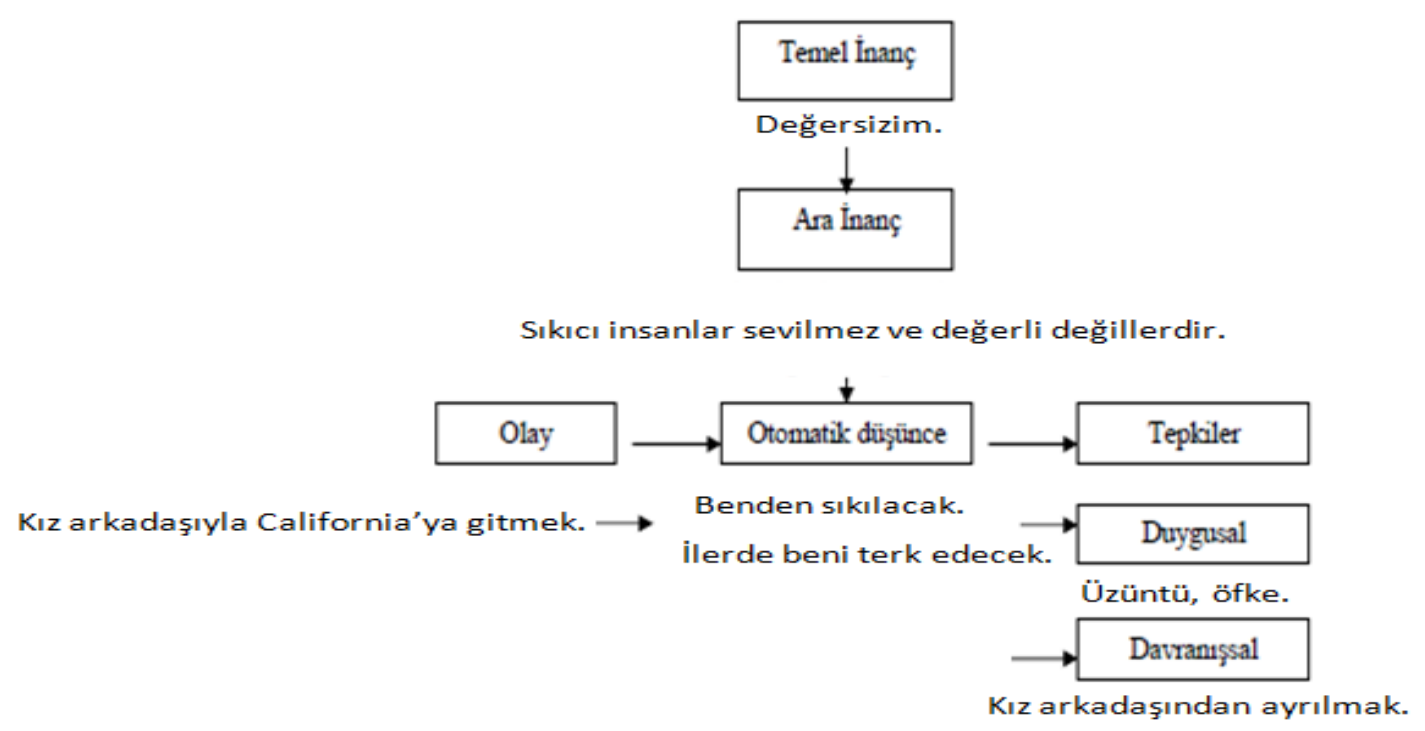

Şekil 1'den gösterildiği gibi Will'in California'ya gitmesini engelleyen ve kız arkadaşından ayrılmasına yol açan çocukluğundan itibaren oluşmaya başlayan değersizim temel inancıdır. Bilişsel davranışçı yaklaşıma göre, erken çocukluk dönemi yaşantıları sonucu oluşan çıkarımların bir kısmı işlevsel özellik taşırken, bir kısmı da işlevsel olmayan çıkarımlardır. İşlevsel olmayan çıkarımlar sonucunda ise kişide olumsuz şemalar gelişir ve herhangi bir yaşam olayı, bireyde var olan olumsuz şemaları tekrar aktif hale getirebilir (O'Donohue ve Dollarhide, 2009; Sharf, 2012). Temel inançlar erken çocukluk döneminden itibaren bireyin anne-babası ile arasındaki ilişkilerinden ve yaşadığı önemli olaylar sonucunda oluşmaktadırlar. Temel inançlar, ara inançlara göre daha kapsamlı ve daha genel konuları içerir. "çaresizim", "değersizim" gibi ifadeler birer temel inanç örneği olarak gösterilebilir (Beck, 2006).

\section{Bilişsel Çarpıtmalar}

Bilişsel çarpıtmalar BDT'nin önemli kavramlarındandır. Beck (2006) BDT'nin en geniş anlamıyla çarpıtılmış düşünceleri düzelterek psikolojik sorunu ortadan kaldırmaya çalışan yaklaşımların tümü olduğunu söylemektedir. Bu sebeple BDT'de danışma sürecinde danışana kendi düşünce ve varsayımlarını, özellikle bilişsel çarpıtmalarını tanımaları gözlemlemeleri ve takip etmeleri öğretilir (Corey, 2015; Dinç, 2012, Gökçakan ve Gökçakan, 2005; O’Donohue ve Dollarhide; Sharf, 2012). Filmin başkahramanı Will'in de davranışlarını ve duygularını yönlendiren bilişsel çarpıtmaları bulunmaktadır. $\mathrm{Bu}$ bölümde filmdeki diyalogların değerlendirilmesiyle; Will'in yapmış olduğu bilişsel çarpıtmalar incelenmiştir.

Keyfi çıkarımlar: Bir olaya ilişkin destekleyici kanıtlar olmaksızın genelleyici sonuçlar çıkarma kastedilmektedir. Keyfi çıkarımlar, felaketleştirmeyi de kapsamaktadır (Corey, 2015). Bu düşünce yapısına sahip kişiler yaşanan herhangi bir olayı farklı açılardan değerlendirmek yerine tamamen iyi ya da tamamen kötü gibi iki uçta değerlendirmektedirler (O'Donohue ve Fisher, 2009). Filmde Will ve terapisti Sean arasında Will'in kız arkadaşıyla ilişkisine yönelik bir konuşma geçer. Will terapistine eğer kız arkadaşıyla daha uzun süre vakit geçirirse onun her yönüyle mükemmel olmadığını fark edeceğini ve ilişkilerinin biteceğini söyler.

Will: Merak etme, ne yaptığımı biliyorum. Bu klz farkll; zeki, eğlenceli tanıdiğım diğer kızlardan farkll.

Sean (Terapist): $O$ zaman arasana.

Will: Neden? O kadar zeki olmadı̆̆ını anlayayım diye mi? 
Sean (Terapist): Kız sikıcı mı?

Will: Şu an için mükemmel. Bunu mahvetmek istemiyorum.

Sean (Terapist): Dünyamıza kimi sokacağımızı kendimiz seçeriz. Hayatta kimse mükemmel değildir sen dâhil. Dolayısıyla tanıştığın o kız yani Skylar da mükemmel değil. Önemli olan birbiriniz için mükemmel misiniz? Önemli olan budur. (Film 57. $D k$.)

Filmin başkahramanı Will birlikte olduğu kız arkadaşı Skylar'ın her konuda mükemmel olmasını beklemektedir. Eğer onunla yeterince vakit geçirirse onun mükemmel olmadığını fark edeceğini ve ilişkisinin biteceğini söylemektedir. Terapisti Sean ve Will arasında geçen diyalog keyfi çıkarımlarda bulunmaya iyi bir örnek oluşturmaktadır. BDT'de terapi sürecinde bu bilişsel çarpıtmalar üzerinde çalışılmaktadır. Terapist bilişsel çarpıtmalara neden olan temel inançları bulmaya çalışmaktadır (Murdock, 2012; Sharf, 2012). Bilişsel yapının açıklandığı bölümde Will'in böyle davranmasına neden olan muhtemel temel inanç açıklanmaya çalışılmıştı.

Aşırı genelleme: Bireyin bir tek nedene ya da olaya bağlı kalarak kendisiyle ya da olayla ilgili genelleme yapması durumudur. $\mathrm{Bu}$ genellemeler çoğunlukla olumsuz ve bireyin uyumunu bozucu olmaktadır (Corey, 2015; Murdock, 2012). Filmde Will ve terapisti arasında aşırı genellemeye örnek oluşturabilecek bir konuşma geçmektedir. Will terapistinin yaptı̆g 1 bir resme bakarak ve onun bütün hayatı hakkında çıkarımlarda bulunmuştur. Bunun üzerine Will ve Sean (terapist) arasında aşağıdaki diyalog geçmiştir.

Sean: Sirf bana ait bir resmi gördügüun için hakkımdaki her şeyi bildiğini Zannediyorsun. Bir resmimle benim bütün hayatımı yorumladın. Sen de bir yetimsin öyle değil mi?

Will:........ (Terapistini başıyla onaylar).

Sean: Peki bu durumda ben de Oliver Twist romanını okuduğum için senin hayatının ilk dönemlerinde neler hissettiğini anlayabilir miyim? Bu seni anlatır mı?

Will:.........(Hayır şeklinde başını sallar).

Sean: Senin hayatına ilişkin her şeyi bilemem. Ĕger sen bana kim olduğunu anlatmak istemezsen sadece yetimleri anlatan bir kitap okudum diye seni anlayamam (Film, Dk. 49).

BDT öğrenme modeline dayalı bir yaklaşımdır. Bu yaklaşımda bireyin yapmış olduğu bilişsel çarpıtmaların farkına varmasına yardımcı olmak amaçlanmaktadır (Beck, 2006; Corey, 2015). Buradaki diyalogda da terapist Will'in insanlara karşı yapmış olduğu aşırı genellemelerin yanlışlığını anlatmaya çalışmaktadır. Ayrıca Sean, BDT'de olduğu gibi terapi sürecinin amacına ulaşabilmesi için danışanın aktif bir şekilde terapi sürecinde rol alması gerektiğini anlatmaktadır.

Falcıllk: Bu düşünce yapısına sahip kişiler elinde var olan düşünceyi destekleyecek yeterli kanıt olmaksızın geleceğe ilişkin olumsuz çıkarımlarda bulunmaktırlar. Falcılık henüz yaşanmamış bir olayı sanki yaşanmış gibi önceki deneyimlere dayanak olumsuz olarak değerlendirme biçimindeki bir bilişsel çarpıtma olarak tanımlanabilir (Murdock, 2012). Falcılık bilişsel çarpıtmasına Will ve kız arkadaşı Skylar arasında bir diyalog geçmektedir. Filmde Will'in kız arkadaşı Skylar, Will'e kendisiyle California'ya gelmemesinin nedenini sorar. Bu konuda Will'in yapmış olduğu konuşma aşağıdaki gibidir.

Will: Sen sadece şehrin diğer yakasından bir çocukla çıkmak istiyorsun. Sonra Stanford'a gideceksin. Ailenin onayını alan zengin birisiyle evleneceksin. Diğer zenginlerle birlikte oturup bir zamanlar nasıl bir çılgınlık yaptı̆̆ını anlatacaksın (Film, Dk. 84). 
Will burada Skylar'ın ne yaşadığını ya da düşündüğünü hiç değerlendirmeden geleceğe ilişkin olumsuz bir çıkarımda bulunmaktadır. Aslında Skylar'ın kendisini sevmediğini sadece çılgınlık yapmak için onunla birlikte olduğunu ifade etmektedir. Bu bilişsel çarpıtmada karşıdakinin ne söylediğinin önemi yoktur, önemli olan bilişsel çarpıtmayı yapanın ne düşündügüdür. Danışan Olayın içeriğine ya da alternatif sonuçlara bakmadan karşısındakinin ne düşündüğünü bildiğini varsaymaktadır. Dolayısıyla karşısındaki ne söylerse söylesin danışan kafasında var olan düşüncelere göre hareket etmektedir (Murdock, 2012).

Diğer bir sahnede Skylar Will'den onunla birlikte California'ya gelmesini ister ve aralarında aşağıdaki diyalog geçer.

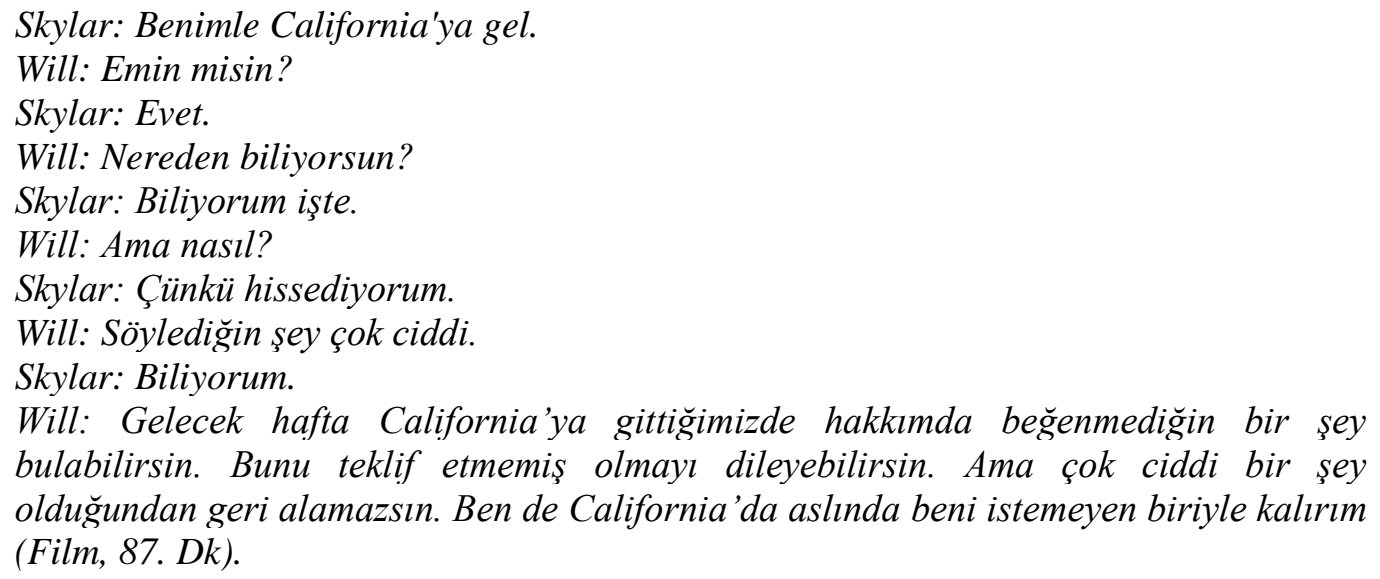

Yukarıda diyalogda olduğu gibi Will diğer olasılıkları değerlendirmeden elinde yeterince kanıt olmadan geleceğe ilişkin kesin ve olumsuz sonuçlara ulaşmaktadır. Will eğer kız arkadaşıyla giderse kız arkadaşının ondan sıkılacağı ve onu terk edeceğini düşünmektedir.

Etiketleme: Etiketlemeyi kullanan danışanlar genellikle içinde bulundukları duruma ya da kişiye ilişkin eldeki bulguları yeterince değerlendirmeden kesin, katı, yargılayıcı ve olumsuz yakıştırmalar kullanmaktadırlar (Corey, 2015; Murdock, 2012). Will okulda matematik profesörünü beklerken orada profesörün asistanıyla arasında bir konuşma geçmektedir. Burada Profesörün asistanı toplumda yapılan etiketlemelere ilişkin bir örnek vermektedir. Asistan: "Çoğu insan ne kadar zeki olduğunu fark etmez. Öğretmenleri onlara güvenmez. Aptal olduklarına inanırlar." Dk.87. Etiketleme sadece kişinin kendine yönelik olmayabilir. Bu bilişsel çarpıtmayı yapan kişiler kendilerini "aptalın tekiyim, işe yaramazım" şeklinde etiketleyebilecekleri gibi, çevresindeki insanları da "tembel, düşüncesiz" gibi etiketleyebilirler. Etiketleme aşırı genelleme bilişsel çarpıtmasıyla benzer bir bilişsel çarpıtmadır (Sharf, 2012). Filmde Will'in de Skylar'a yapmış olduğu etiketlemeler de bulunmaktadır. Örnek verilecek olursa Will kız arkadaşı Skylar'1 zengin şımarık ve ileride onu terk edecek birisi olarak görmektedir. Ayrıca Will'in kafasında zengin insanlara yönelik yapmış olduğu etiketlemelerde filmde bolca kullanılmaktadır.

\section{Danışan Terapist İliş̧kisi:}

Diğer terapi yaklaşımlarında olduğu gibi BDT'de de terapinin amaçlarına ulaşabilmesi için terapist ile danışan arasında sağlam bir terapötik işbirliği gereklidir. Terapinin amacına ulaşabilmesi için terapist danışanıyla saygı, empati ve güvene dayalı bir terapötik ilişki kurmak durumundadır (Corey, 2015). Filmde terapist olan Sean Maguire üniversitede öğrencilerine ders verirken terapötik sürecin nasıl olması gerektiğini anlatır.

Sean: Güven bir ilişkide çok önemlidir. Klinik durumlarda da çok önemlidir. Bir hastayla aşama kaydetmek için güven neden önemlidir? Vinnie güven neden önemlidir? 
Vinnie (Öğrencilerden birisi): Çünkü güven... Çünkü güven hayattır.

Sean: Çok derin oldu. Teşekkürler Vinnie. Hastanız size güvenmezse size karşı dürüst olmaz. O zaman terapinin bir anlamı kalmaz (Film, Dk. 33).

BDT yaklaşımında da danışan ve terapistin ilişkisi oldukça önemli görülmektedir. $\mathrm{Bu}$ ilişki karşılıklı güvene dayalı bir ilişkidir. Eğer terapi sürecinde güven oluşmazsa terapi amacına ulaşamaz. Danışan ve terapist arasında oluşturulan ilişki güvene ve işbirliğine dayalı olmalıdır. $\mathrm{Bu}$ sebeple diğer bir çok terapi yaklaşımında olduğu gibi BDT'de terapist ilk görüşmeden itibaren güven temelli terapötik bir ilişki kurmaya çalışmaktadır (Beck, 2006; Corey, 2015; Sharf, 2012). Terapötik ilişkinin vurgulandığ 1 durumlara filmde de örnek durumlar bulunmaktadır. Filmde artık danışma oturumları bitmiştir. Sean ve Will vedalaşırlar. Vedalaşırken birbirlerine sarılırlar.

Will: Teşekkür ederim Sean.

Sean: Teşekkür ederim Will.

(Burada Sean ve Will birbirlerine sarllirlar.)

Will: Bu terapist danışan ilişkisini ihlal etmek değil mi?

Sean: Kalçamı tutmazsan değil. Gülüşmeler (Film, Dk. 114).

Artık terapi bitmiştir, ancak Will ve terapist izleme çalışmaları için tekrar görüşeceklerdir. $\mathrm{Bu}$ filmde terapi süreci başarıya ulaşılmıştır. Diyaloglardan ve fillmdeki sahneden de anlaşılacağı gibi Will ve Sean arasında güvene dayalı sıcak bir ilişki oluşmuştur. Filmde vurgulanan terapinin başarıya ulaşmasını sağlayan; terapist ve danışan arasındaki güvene dayanan sıcak bir ilişkidir. BDT'de de terapi sürecinin amacına ulaşabilmesi için danışan ve terapistin kuracağı ilişki hayati önem taşımaktadır (Beck, 2006).

\section{Sonuç ve Öneriler}

Filmler psikoloji alanında ve psikolojik danışman eğitiminde yardımcı bir araç olarak kullanılabilmektedir (Aka ve Gençöz, 2010; Koch ve Dollarhide, 2000; Sharp ve diğ., 2002; Smithikrai, 2016). Alanyazında sinemanın psikoloji ve psikolojik danışma gibi alanlarda kullanılmasının önemi vurgulanmaktadır (Aka ve Gençöz, 2010; Hankir ve diğ., 2016 Koch ve Dollarhide, 2000; Smithikrai, 2016), ancak Türkiye'de bu konuda yapılan çalışmaların sayısının oldukça az olduğu görülmektedir (Acar ve Voltan-Acar, 2013; Horzum, 2011; Kağnıc1, 2015; Tümlü ve Voltan-Acar, 2014). Ayrıca filmler kuramlara örnek oluşturması ve kuramsal bilgiyi somutlaştırmak amacıyla da kullanılmaktadır (Morsünbül, 2015; Şenol-Durak ve Fişıloğlu, 2007). BDT'de günümüzde sosyal fobiden, uykusuzluğa ve saldırganlığa kadar bir çok sorunun çözümünde yaygın olarak uygulanan terapi yaklaşımlarından birisidir (Bloom ve diğ., 2015; El Alaoui ve diğ., 2015; Tekinsav-Sütçü ve diğ., 2010). Bu çalışmada BDT’nin kuramsal çerçevesi; bilişsel yapı, otomatik düşünceler, temel inançlar, bilişsel şemalar, bilişsel çarpıtmalar ve terapötik ilişki gibi kuramın temel kavramları film analizi yardımıyla açıklanmıştır. BDT’nin temel kavramlarını açıklamak amacıyla Can Dostum isimli film analiz edilmiştir.

$\mathrm{Bu}$ çalışmada analiz edilen filmin başkahramanı Will'in saldırgan davranış problemi bulunmaktadır. Saldırganlık, zorbalık, öfke ve şiddet bireyin topluma uyumunu bozmakta ve okul terkinden depresyona kadar birçok farklı soruna neden olabilmektedir (Boyacı, 2016; De Rubeis ve Granic, 2012; Feindler ve Engel, 2011; Olweus, 2013). BDT'ye göre kişinin özgüvenini olumsuz etkileyen, kendini yalnız hissetmesine neden olan ve saldırganca davranışlarda bulunmasına neden olan bilişsel şemalar ve çarpıtmalardır (Tekinsav-Sütçü ve diğ., 2010). Bu bilişsel yapılar, filmin başkahramanı Will'i etkilediği gibi gerçek yaşamdaki insanları da olumsuz yönde etkileyebilmektedir. Bu bilişsel yapıların varlığı, felaketleştirme (kız arkadaşımla gitsem bile benden sıkılacak ve beni terk edecek), ya hep ya da hiç düşünme (bir insan ya mükemmeldir ya da değildir), etiketleme (bütün zenginler züppedir.) gibi bilişsel çarpıtmalara yol açabilir. Bu bilişsel çarpıtmalar da bireyin dünyaya bakışını olumsuz yönde 
etkilemektedir. Bu film özellikle bilişsel çarpıtmalara örnek oluşturması ve saldırgan davranış problemine değindiği için seçilmiştir. Filmde terapist rolündeki Sean gibi BDT'de de terapistler, danışanlarının bilişsel yapılarını tespit edip yaşamını olumsuz yönde etkileyen bilişsel çarpıtmaları değiştirmeye çalışmaktadırlar (Corey, 2015; Murdock, 2012).

Filmin başkahramanı olan Will'in saldırgan davranışlarının temelinde çocukluk yıllarında yaşamış olduğu aile içi şiddetin etkili olduğu görülmektedir. Alanyazın incelendiğinde gençlerde ve çocuklarda saldırgan davranışının oluşmasında aile yaşantısının belirleyici olduğu görülmektedir (Tekinsav-Sütçü ve diğ., 2010). Bilişsel davranışçı yaklaşım saldırgan davranışı ortadan kaldırmak için bir araç olarak kullanılmaktadır (De Rubeis ve Granic, 2012; Redondo ve diğ., 2013) ancak saldırgan davranışın ortaya çıkmadan aile içinde okulda önleyici çalışmaların yapılması gerekmektedir (Boyac1, 2016; Stefanakou, Tsiantis ve Tsiantis, 2014). Film, tiyatro, kitap ve müzik gibi sanat eserlerinin eğitici özellikleri de bulunmaktadır (Berk, 2009; Hankir ve diğ., 2016; Şenol-Durak ve Fiş1loğlu, 2007; Tümlü ve Voltan-Acar, 2014). Bu çalışmada da BDT'ye ve temel kavramlarına bir film aracılığıyla örneklendirme oluşturulmaya çalışılmıştır. Can Dostum/Good Will Hunting gösterime girdiği 1997 senesinde en iyi senaryo Oscar ödülünü kazanmış ve bilinen bir filmdir. Bu çalışmada böyle geniş kitlelerin seyrettiği ödüllü bir film üzerinden BDT'nin temel kavramlarının açıklanmasının alana katkı sağlayacağı düşünülmektedir. Dolayısıyla bundan sonraki çalışmalarda da film, kitap gibi farklı materyaller kullanılarak alandaki bilgi birikimi genişletilebilir. Bu çalışmada BDT'nin sınırlı sayıdaki temel kavramı incelenmişsir. İlerde yapılacak benzer çalışmalarda diğer bilişsel çarpıtmalara örnek oluşturabilecek filmler analiz edilebilir. Ayrıca üniversitelerde derslerde kuramlara ilişkin somut birer örnek sunulması adına bu filmlerin kullanılması, ilgili konularının daha iyi anlaşılmasına katkı sağlayabilir. Son olarak, danışanlara sorunların çözümüne katkı sağlamak için bibliyoterapi bir teknik olarak kullanılmaktadır. Benzer şekilde danışanların sorunlarına daha faklı açılardan bakabilmelerine yardımcı olmak için filmler bu açıdan kullanılabilir.

\section{Kaynaklar}

Acar, T. ve Voltan-Acar, N. (2013). "Babam ve Oğlum” filminin çok kuşaklı/kuşaklararası aile terapisinin temel kavramları açısından değerlendirilmesi. Kuram ve Uygulamada Eğitim Bilimleri, 13(1), 37-53.

Aka, B. T. ve Gençöz, F. (2010). Sinematerapinin mükemmeliyetçilik ve mükemmeliyetçilikle ilgili şemalar üzerindeki etkisi. Türk Psikoloji Dergisi, 25(65), 69-77.

Beck, A.T. (2006). Bilişsel terapi ve duygusal bozukluklar. (Çev: A, Türkcan). İstanbul: Litera Yayınc1lik.

Berk, R. A. (2009). Multimedia teaching with video clips: TV, movies, youtube, and mtvu in the college classroom. International Journal of Technology in Teaching and Learning, $5(1), 1-21$.

Blom, K., Tillgren, H. T., Wiklund, T., Danlycke, E., Forssen, M., Söderström, A., ... \& Andersson, G. (2015). Internet-vs. group-delivered cognitive behavior therapy for insomnia: A randomized controlled non-inferiority trial. Behaviour Research and Therapy, 70, 47-55.

Boyacı, M. (2016). Psikoeğitsel müdahale programının okul öncesi (60-72 ay) çocukların saldırgan davranışlarına etkisi / effect of the psychoeducational intervention program on aggressive behaviors of preschool children (60-72 month). TURKISH STUDIES International Periodical for the Languages, Literature and History of Turkish or Turkic-, ISSN: 1308-2140, (Prof. Dr. Hayati Akyol Armağanı), Volume 11/3 Winter 2016, DOI Number: http://dx.doi.org/10.7827/TurkishStudies.9065, p. 573-588. 
Boyac1 \& İlhan

Corey, G. (2015). Theory and practice of counseling and psychotherapy. Nelson Education.

Dinç, M. (2012). Aaron temkin beck: eleştirel düşüncenin peşinden yaratıcı bir psikoterapi kuramına. Bilişsel Davranışçı Psikoterapi ve Araştırmalar Dergisi,1 (1), 70-76.

De Rubeis, S., \& Granic, I. (2012). Understanding treatment effectiveness for aggressive youth: The importance of regulation in mother-child interactions. Journal of Family Psychology, 26(1), 66.

El Alaoui, S., Hedman, E., Kaldo, V., Hesser, H., Kraepelien, M., Andersson, E., \& Lindefors, N. (2015). Effectiveness of Internet-based cognitive-behavior therapy for social anxiety disorder in clinical psychiatry. Journal of Consulting and Clinical Psychology, 83(5), 902-915.

Feindler, E. L., \& Engel, E. C. (2011). Assessment and intervention for adolescents with anger and aggression difficulties in school settings. Psychology in the Schools, 48(3), 243253.

Goodson, I., \& Walker, R. (1988). Putting Life into Educational Research. In R. R. Sherman \& R.B.Webb (Eds). Qualitative research in education: focus and methods (pp. 108-122). London: Routledge.

Gökçakan, Z. ve Gökçakan, N. (2005). Depresyonda bilişsel terapi. Mersin Üniversitesi Eğitim Fakültesi Dergisi, 1 (1), 91-101.

Hankir, A., Holloway, D., Agius, M., \& Zaman, R. (2015). Beyond a beautiful mind: film as an educational and therapeutic tool. European Psychiatry, 30 (0), 1901-1912.

Horzum, I. (2011). Dövüş kulübü filminin ruhbilimsel çözümlemesi. Akademik Bakış Dergisi, $25,1-24$.

Hunt, E. F., \& Colander, D. C. (2015). Social science: an introduction to the study of society. (Fifteenth Edition). New-York: Routledge.

Kağnıcı, D. Y. (2015). Psikolojik danışman eğitiminde cinsel yönelim olgusunun irdelenmesi: benim çocuğum filmi. Türk Psikolojik Danışma ve Rehberlik Dergisi, 5(44), 83-95.

Koch, G., \& Dollarhide, C. T. (2000). Using a popular film in counselor education: good will hunting as a teaching tool. Counselor Education and Supervision, 39(3), 203-210.

Morsünbül, Ü. (2015). Analyzing honey (bal), milk (süt) and egg (yumurta) movies in terms of erikson's theory of psychosocial development. Elementary Education Online, 14(1), 181-187.

Murdock, N. L. (2012). Theories of counseling and psychotherapy: a case approach. Pearson Higher Ed.

O'Donohue, W. T., \& Fisher, J. E. (Eds.). (2009). General principles and empirically supported techniques of cognitive behavior therapy. John Wiley \& Sons.

Olweus, D. (2013). School bullying: development and some important challenges. Annual Review of Clinical Psychology, 9, 751-780.

Redondo, S., Martínez-Catena, A., \& Andrés-Pueyo, A. (2012). Therapeutic effects of a cognitive-behavioural treatment with juvenile offenders. The European Journal of Psychology Applied to Legal Context, 4(2), 159-178.

Sharf, R.S. (2012). Theories of Psychotherapy and Counseling: Concepts and Cases. (5th ed.). USA: Cengage Learning Products.

Sharp, C., Smith, J. V., \& Cole, A. (2002). Cinematherapy: metaphorically promoting therapeutic change. Counselling Psychology Quarterly, 15(3), 269-276. 
Smithikrai, C. (2016). Effectiveness of teaching with movies to promote positive characteristics and behaviors. Procedia-Social and Behavioral Sciences, 217, 522-530.

Stefanakou, A., Tsiantis, A. C., \& Tsiantis, J. (2014). A review of anti-bullying prevention and intervention programmes in Greece. International Journal of Mental Health Promotion, 16(1), 19-27.

Şenol-Durak, E. ve Fışıloğlu, H. (2007). Film analizi yöntemi ile virginia satir aile terapisi yaklaşımına bir bakış. Türk Psikoloji Yazıları, 10 (20), 43-62.

Tekinsav-Sütcü, S., Aydın, A. ve Sorias, O. (2010). Ergenlerde öfke ve saldırganlığ1 azaltmak için bilişsel davranışçı bir grup terapisi programının etkililiği. Türk Psikoloji Dergisi, 25 (66), 57-67.

Tümlü, G. Ü. ve Acar, N. V. (2014). Issız adam filminin gerçeklik terapisine dayalı incelenmesi. Insan \& Insan, 2(1), 62-73.

Yıldırım, A. ve Şimşek, H. (2013). Sosyal bilimlerde nitel araştırma yöntemleri (9. Genişletilmiş Baskı). Ankara: Seçkin Yayıncılık.

\section{Extended Abstract}

\section{Introduction}

A person maintains his/her life and meets his/her needs by communicating other people within society. In this communication process, conflicts may arise as well time to time (Hunt \& Colander, 2015). So people need professional support to overcome these conflicts (Corey, 2015). One of the methods widely used to help people to solve their problems is the CBT approach (Blom et al., 2015; El Alaoui et al, 2015; Redondo, Martinez-Catena \& Andres-Pueyo, 2012). According to this approach, the emotional and behavioral problems which a person faces are based on his/her cognitive structure. Hence these emotional and behavioral problems may disappear in case this problematic mentality of the person is changed (Beck, 2006). Within the CBT approach, the problematic thoughts which are seen as the source of the behavior are analyzed. The therapist and client try to find the cognitive distortion breaking the balance of the client and change them. The client is taught to recognize, observe and follow his/her own thoughts and assumptions especially the negative automatic thoughts within the counseling process (Sharf, 2012).

In this study the movie of "Good Will Hunting" which won two Oscars has been analyzed to form an example for the basic norms and implementations of the Cognitive Behavioral Therapy. Today movies are one of the means benefitted for various research areas such as education, psychology and psychological counseling concerning people and society closely (Berk, 2009; Hankir, Holloway, Agius \& Zaman, 2015; Kağnıc1, 2015; Koch \& Dollardhide, 2000). Movies illustrate life of people partially and sometimes they are formed by being inspired from real life stories. In this sense, movies are increasingly used as a means helping the therapy process within literature in recent years (Horzum, 2011; Morsünbül, 2015; Sharp, Smith \& Cole, 2002; Smithikrai, 2016). In this way, the person can look at the facts which he/she faced from a different aspect and observe corporally different solutions with their probable results thanks to the movies. (Aka \& Gençöz, 2010). In this regard, it is thought that this study will contribute to psychological counseling training and psychology.

\section{Method}

In the study one of the qualitative research methods document analyses were used. Movies are accepted important means for training. In the document review, the investigation involves the analysis of written and visual materials that provide information about the intended subjects 
(Goodson \& Walker, 1988). Thanks to their use for training, students' attention could be easily drawn to the topic. So in this way the topic and learning process can be more interesting (Berk, 2009). The CBT is one the therapy approaches commonly used for many problems from social phobia to insomnia and aggression (Blom et al., 2015; O'Donohue \& Fisher, 2009). In this study, the basic norms of the CBT have been tried to be exemplified and embodied. In this way, it has been aimed to contribute to researchers and students working on the theoretical part of this issue. In addition, some explanations about the reason and treatment process of aggressive behaviors have been included within the context of the CBT in this study.

In this study, the relation between Will Hunting who is a highly gifted young and working as a cleaner at the university because of having dropped out of school due to his aggressive behaviors and his therapist Sean has been analyzed in terms of the CBT approach. Although Will Hunting, the young leading man of the movie, is highly gifted especially in Mathematics, he has been sent into a detention center many times due to his aggressive behaviors and dropped out of the school. In this study "Good Will Hunting" movie had been chosen to form an example for some frequent behavioral problems such as aggression and bullying within society (De Rubeis \& Granic, 2012; Feindler \& Engel, 2011). It is also an important example for reflecting the relation between the psychological counselor and client. The CBT method is commonly used within the implementations of both group counseling and individual counseling with the clients having the problem of aggressive behaviors.

\section{Result and Discussion}

Will, who is the main character of the movie had an aggressive behavior problem. According to the CBT approach, the cognitive schemas and distortions affect a person's self-confidence negatively and cause to feel alone besides aggressive behaviors (Tekinsav-Sütcü et al, 2010). These cognitive schemas may affect young people within society just like to Will, the main character of the movie. Presence of these cognitive schemas may cause to some cognitive distortions such as Catastrophizing (even if I go with my girlfriend, she would be bored and leave), All or nothing thinking (a person may be either excellent or not), Labeling (all rich people are snob). So these cognitive distortions affect a person's point of world view negatively (Corey, 2015; O'Donohue \& Fisher, 2009). This movie is important in terms of being an example of cognitive distortions and focusing on the problem of aggressive behaviors. Therapists in the CBT approach tries to change the cognitive distortions affecting people's life negatively after depicting the cognitive structure of their clients like Sean in the role of a therapist in the movie.

The aggressive behaviors of Will are based on the family violence which Will exposed in his childhood. When literature is analyzed on this issue, it is seen that family life may trigger this kind of aggressive behaviors on young people and children (De Rubeis \& Granic, 2012). The cognitive behavioral approach is used as a means to eradicate the aggressive behaviors (Tekinsav-Sütçü et al, 2010). However, the easiest way to avoid this kind of behaviors is to resolve them within the family before they become apparent (Stefanakou, Tsiantis \& Tsiantis, 2014). Therefore studies carried out with families are important and needed to prevent this kind of problems before their appearance within society. As a result, film, theatre and music include instructive points as well (Acar ve Voltan-Acar, 2013; Berk, 2009; Tümlü \& Voltan-Acar, 2014). In this study, the CBT and norms of this therapy approach have been tried to be exemplified through this movie. Good Will Hunting movie released in 1997 won Oscar for the best scenario, so it is a well know movie. In this sense, it is thought that explaining the basic norms of the CBT through this well-known and awarded movie would be beneficial for the field. As this kind of studies in literature increase, it would contribute to the rise of current materials used for the training of psychological counseling (Koch \& Dollarhide, 2000). Psychological counselors in Turkey generally work with children in schools. For this reason, materials which can mostly affect children such as animation or cartoons could be used for educational purposes by researchers. 